\title{
Türk Muhasebe ve Finans Yazınının SSCI'da 20 Yılı
}

\author{
Gönül ALKAN* \\ Hakan ÖZKAYA**
}

\section{ÖZET}

Bu çalışmanın amacı Türk finans ve muhasebe yazınının Web of Science SSCI'da (Social Science Citation Index) endekslenen dergiler kapsamında genel bir görünümünün ortaya konmasıdır. Analiz sonuçlarına göre 75 farklı dergide toplamda 398 finans ve muhasebe alanında akademik çalışma yayınlanmıştır. Bu çalışmalar yayınlandıkları dergiler bağlamında değerlendirildiğinde yüksek bir yoğunlaşma görülmektedir. En fazla akademik çalışmanın yayınlandığı ilk dört dergide sirası ile 88, 76, 34 ve 17 adet çalışma yayınlanmıştır. Bir başska deyişle 75 dergiden 4 'ünün toplam çalıșma sayısının yarısından fazlasını (\%54) yayınladiğ görülmektedir. Yayınların yıllar bağlamında değerlendirilmesinde de benzer yüksek dereceli bir yoğunlaşma ile karşılaşılmaktadır. 398 çalışmanın 316 'sı (\%80) son 6 yll içinde yayınlanmıştır. SSCI'da yayınlanan makalelerin sayısında yıllar içinde bir artış trendi gözlenmiştir. Çalışmanın bir diğer ilginç bulgusu 1980 yılından 1994 yılına kadar tek bir çalışmanın dahi yayınlanmamış olmasıdır. Yazar sayısı açısından değerlendirildiğinde çalışmaların çoğunlukla 2 yazar tarafindan yazıldiğı görülmektedir. 4 veya daha fazla yazarlı akademik çallşmalar ise çok nadir olarak görülmektedir.

Anahtar Kelimeler: Türk Finans ve Muhasebe Yazını, Social Science Citation Index, Bibliyometri.

JEL Sinıflandırması: M40,I21.

\section{Years of Turkish Finance and Accounting Literature in SSCI ABSTRACT}

The purpose of this study is to provide a general view of Turkish Finance and Accounting ( $F \& A$ ) literature in the context of journals that are indexed in SSCI (Social Science Citation Index) of Web of Science. Results show that; total 398 F\&A articles were published in 75 different journals. We observe a high level of concentration in terms of journals. Top four journals published; 88, 76, 34 and 17 papers respectively. That is 4 out of 75 journals account for more than half of the academic work. We also observe a high level of concentration in terms of publication years as well. 316 out of 398 academic works were published in the last 6 years. There is an upwards trend in the number of publications in SSCI. One of the interesting findings of the study is that there is not even a single study from 1980 to 1994. When we look at the number of authors; we see that academic works in Turkey were done mostly by 2 authors and academic works done by 4 or 5 authors are rare.

Keywords: Turkish Finance and Accounting Literature, Social Science Citation Index, Bibliometrics.

Jel Classification: M40,I21.

\footnotetext{
*Yrd.Doç.Dr. Gönül Alkan, Dokuz Eylül Üniversitesi, İzmir Meslek Yüksekokulu, gonul.ipek@deu.edu.tr

** Yrd.Doç.Dr.Hakan Özkaya,Pamukkale Üniversitesi, İktisadi ve İdari Bilimler Fakültesi, hozkaya@pau.edu.tr
} 


\section{GíRiş}

Bilimsel çalışma yapmanın temel amacı elde edilen bulguların geniş kitlelere aktarılmasıdır. Bibliyometrik araştırmalar yayınların farklı yöntemlerle analiz edilmesine ve bilimsel amaçlı çalışmaların değerlendirilmesine olanak sağlayan araştırmalardır. $\mathrm{Bu}$ bağlamda bibliyometrik yöntemler bilimsel çalışmaların sonuçlarının ve etkinliğinin ölçülmesini sağlar. Bibliyometrik araştırmalar bilim dallarının kendi alanlarındaki yayın yeterliliğini; yayın sayısı, yayın niteliği, yayın yapılan dergilerin ait olduğu endekslerin seçimi gibi kriterler 1şı̆̆ında değerlendirerek geleceğe yönelik bilim politikalarının oluşturulmasına yardımcı olur.

Bibliyometri, akademik yayınların çeşitli unsurlarının (yazar, konu, yıl, sayfa sayısı, yapılan atıflar vb.) sayısal analizler ve istatistikler yardımıyla incelenmesi ile ilgilenmektedir. Bibliyometrik analizler tanımlayıcı nitelikte (belirli bir yılda yayımlanan makale sayısının belirlenmesi) olabileceği gibi, değerlendirici nitelikte de (bir makalenin kendisinden sonra gelen araştırmaları ne şekilde etkilediğini ortaya koymak için atıf analizi yapılması) olabilirler (McBurney ve Novak, 2002:40).

Bibliyometrik araştırmalar ile bir ülkenin bilimsel yayın politikası değerlendirilebileceği gibi, araştırmacıların ya da kurumların yayın performanslarını da ölçmek olanaklıdır. Çeşitli bibliyometrik göstergeler (atıf almayan yayınların oranı, hendeksi, toplam atıf sayısı gibi) aracılığıyla ülkelerin bilimsel yayın yapma davranışları ortaya konulabilmektedir (A1,2008:265).

Bibliyometrik çalışmaların kişisel ve kurumsal olarak bilimsel yayıncılıkta hangi düzeyde olduğumuzun göstergeleri olduğunu belirtmektedir (Al, Al ve Bahşişoğlu,2004)

$\mathrm{Bu}$ bağlamda bu araştırma Türkiye'deki muhasebe-finansman alanının ve bilim insanlarının, uluslararası yayın kategorisindeki performansıyla ilgili bulgular sunmaktadır.

Türkiye adresli Web of Science'de yayınlanan muhasebe - finansman alanındaki bilimsel çalışmaların genel perspektifini ortaya koymak amacıyla yapılan bu araştırma; geleceğe yönelik muhasebe -finansman alanında yayın sayısını ve niteliğini arttırmak için yapılması gerekenlere ilişkin tartışma ortamı oluşturmayı hedeflemektedir.

\section{KAVRAMSAL ÇERÇEVE}

Araştırma, "bilginin bulunması, geliştirilmesi ve gerçeğe uygun olup olmadığının kontrol edilmesi için harcanan çaba" dır (Arslantürk, 1995: 14). Bilimsel araştırmalar, bilim ve teknoloji alanının ve toplumun gelişmesinin en dinamik unsurunu oluştururlar. Ülkelerin bilim ve teknolojideki gelişmişliğini ölçmenin en önemli göstergelerinden biri uluslararası bilimsel atıf indekslerine (SCI, SSCI, A\&HCI) giren yayın sayısıdır. Uluslararası ortak kabule göre, ülkelerin dünya bilimsel üretimine katkılarının düzeyi, diğer ölçütler de olmakla birlikte, özellikle bu endekslerde yer alan makale sayısı ve bunlara yapılan atıflarla belirlenmektedir (Y1lmaz, 2002:47). 
SCI ( Science Citation Index ) bilim ve teknik konularını kapsarken, sosyal bilimler ve insani bilimler alanlarında iki temel veri tabanı mevcuttur. Social Science Citation Index (SSCI) ve Arts and Humanities Citation Index (A\&HCI). WOS (Web of Science, sosyal ve teknik bilimler, tıp ve sağlık bilimleri ve sanat konularında makaleleri ve makalelerin kaynakçalarını listeleyen bibliyografik bir veri tabanı), dünyanın en saygın, etki faktörü (bir derginin geçmiş iki yılda yayımladığı makalelerin toplamına o yıl içerisinde alınan atıfların, geçmiş iki yıl içinde yayımlanan makale sayısına oranı) en yüksek dergilere ait makalelerin yer aldığı, her hafta güncellenen bir veri tabanıdır (Yavan, 2005: 33). SSCI felsefe, coğrafya (beşeri), endüstriyel ilişkiler, hukuk, kütüphanecilik, iktisat, işletme, psikoloji, sosyoloji, antropoloji, kamu yönetimi ve siyaset bilimi, şehir uluslararası ilişkiler gibi sosyal bilimler alanının kapsayan çalışmaların yer aldığı veri tabanı ve atıf dizinidir. SSCI'da 2013 yılı itibariyle 3126 dergi endekslenmektedir. Web of Science'dan alınan dergi atıflarının işlenip, değerlendirilip, hesaplanarak sunumu ise JCR (Journal Citation Reports) aracılığı ile yapılır.

Bibliyometrik araştırmalar bilim dallarının kendi alanlarındaki yayın yeterliliğini; yayın sayısı, yayın niteliği, yayın yapılan dergilerin ait olduğu endekslerin seçimi gibi kriterler 1şı̆̆ında değerlendirerek geleceğe yönelik bilim politikalarının oluşturulmasına yardımcı olur. Bibliyometrik araştırmalarda bazen bir veri tabanındaki yayınların tamamı bazen de bir dönem aralığında bir dergide yer alan makaleler incelenmektedir. Çeşitli veri tabanlarında yayınlanan Türkiye adresli çalışmalara yönelik araştırmalar Tablo 1'de özetlenmiştir.

Tablo 1. Veri Tabanlarında Türkiye Adresli Yayınlara Yönelik Araştırmalar

\begin{tabular}{|c|c|c|}
\hline Veri Tabanı & Konu & Yazar \\
\hline SSCI\&AHCI & $\begin{array}{l}\text { 1970-1999 yılları arasında yayınlanan Türkiye adresli } \\
\text { sosyal bilimler alanındaki yayınlarının bibliyometrik } \\
\text { analizi. }\end{array}$ & $\begin{array}{l}\text { (2002), Gülgöz, } \\
\text { Yedekçioğlu, Yurtsever. }\end{array}$ \\
\hline $\begin{array}{l}\text { SSCI\&AHCI, SCI, } \\
\text { JCR }\end{array}$ & $\begin{array}{l}\text { Atıf Dizinlerindeki Türkiye Adresli Dergilerin } \\
\text { incelenmesi. }\end{array}$ & (2011), Al ve Soydal. \\
\hline SSCI & $\begin{array}{l}\text { 1985-1996 yılları arasında yayınlanan Türkiye adresli } \\
\text { makalelerin bibliyometrik analizi. }\end{array}$ & (1997), Tonta ve İlhan. \\
\hline $\begin{array}{l}\text { SSCI, TÜBİTAK- } \\
\text { ULAKBİM }\end{array}$ & $\begin{array}{lllll}2002-2005 & \text { yılları } & \text { arasında } & \text { çıkan } & \text { yayınları } \\
\text { incelenmesi. } & & & & \\
\end{array}$ & $\begin{array}{lll}\text { (2009), } & \text { Gossart } & \text { ve } \\
\text { Özman. } & & \\
\end{array}$ \\
\hline SSCI & $\begin{array}{l}\text { Türk Psikoloji Dergisi’nde 1995-2005 yılları arasında } \\
\text { yayınlanan makalelerin analizi. }\end{array}$ & (2007), Al ve Coştur. \\
\hline WOK & $\begin{array}{l}\text { Web of Knowledge'da Türkiye adresli Psikoloji } \\
\text { yayınlarının genel değerlendirilmesi. }\end{array}$ & (2013), Arık. \\
\hline SSCI & $\begin{array}{l}\text { Uluslararası alan indekslerinde Türkiye pazarlama } \\
\text { yazınının bibliyometrik analizi. }\end{array}$ & (2013), Şakar ve Cerit. \\
\hline
\end{tabular}


Garfield tarafindan ilk kez Science dergisinde ortaya atılan etki faktörü (impact factor) düşüncesi 1960'ların başında Garfield ve çalışanı Sher SCI için dergiler seçmeye yardımcı olması için dergi etki faktörüne dönüşmüştür. Alanında büyük, önemli ve çok sayıda atıf alan dergilerin SCI indeksinde taranması gerekiyordu. Bununla birlikte küçük ama önemli bazı dergilerinde SCI'da taranması gerekiyordu. Fakat sadece yayın ya da atıf sayısına bağlı kalınırsa bu tip küçük dergiler SCI için seçilemezdi. İşte dergilerin büyüklüğüne ve boyutuna bakmaksızın onları birbiriyle kıyaslayacak basit bir yönteme ihtiyaç duyulması sonucunda dergi etki faktörü ortaya çıkmıştır (Garfield, 1999:979). Etki faktörü (impact factor = IF) değeri, bir dergide o yıl alınan atıfların, önceki 2 yılda çıkan yayın sayısına bölünmesiyle elde edilir.

\section{MUHASEBE VE FINANS ALANININ DEĞERLENDİRILMESINE YÖNELIK ÇALIŞMALAR}

Muhasebe ve finans alanı ile ilgili çalışmalar incelendiğinde çalışmaların aşağıdaki boyutlarda yoğunlaştığı görülmektedir.

- Belirli bir dönem aralığında yayınlanan çalışmaların incelenmesi,

- Belirli bir dönem aralığında bir veya birden çok dergide yayınlanan çalışmaların incelenmesi,

- Belirli bir konuda yayınlanan çalışmaların alan yazınında incelenerek yaşlanmasının değerlendirilmesi,

- Bildiri kitaplarında yayınlanan çalışmaların yöntem ve içerik açısından incelenmesi,

Tablo 2'de muhasebe-finans ve denetim alanında alan yazınının değerlendirilmesine yönelik olarak dünyada yapılan çalışmalar özetlenmiştir.

Tablo 2. Muhasebe-Finansman ve Denetim Alanında Yapılan Çalışmalar

\begin{tabular}{|l|l|l|}
\hline Yıl & Konu & Yazar \\
\hline 1996 & $\begin{array}{l}\text { 1980-1993 yılları arasında yayımlanan makalelerdeki muhasebe } \\
\text { araştırmaları ve araştırma yöntemleri }\end{array}$ & Prather ve Rueschhoff \\
\hline 1996 & $\begin{array}{l}\text { Muhasebe araştırmaları dergilerinin indexleri ve elektronik veri } \\
\text { tabanları açısından değerlendirilmesi }\end{array}$ & Zeff \\
\hline 2000 & Çin'deki muhasebe araştırmaları, & Dong \\
\hline $\mathbf{2 0 0 1}$ & $\begin{array}{l}\text { Behavioral Research in Accounting'de 1989-1998 yılları } \\
\text { arasında çıkan makaleleri incelenmesi, }\end{array}$ & Meyer ve Rigsby, \\
\hline $\mathbf{2 0 0 3}$ & $\begin{array}{l}\text { Journal of American Taxation Association'de 1979-2000 } \\
\text { yılları arasında yayınlanan makalelerin incelenmesi, }\end{array}$ & Hutchison ve White \\
\hline
\end{tabular}




\begin{tabular}{|l|l|l|}
\hline 2004 & İspanya'daki muhasebe yayınları, & Diaz \\
\hline 2004 & $\begin{array}{l}\text { 1992-2001 yılları arasında Accounting Education: An } \\
\text { International Journal'da yayınlanan muhasebe eğitimi ile ilgili } \\
\text { makalelerin incelenmesi, }\end{array}$ & $\begin{array}{l}\text { Catriona Paisey \& } \\
\text { Nicholas J. Paisey }\end{array}$ \\
\hline $\mathbf{2 0 0 6}$ & $\begin{array}{l}\text { Advances in Accounting'de 1984-2003 yılları arasında } \\
\text { yayınlanan makalelerin içerik, araştırma yöntemi ve } \\
\text { yazarlara göre incelenmesi, }\end{array}$ & Mc Millan ve Guffey \\
\hline 2007 & $\begin{array}{l}\text { İtalya'daki muhasebe araştırmaları, } \\
\text { International Journal, Advances in Accounting Education, Global } \\
\text { Perspectives on Accounting Education,Issues in Accounting } \\
\text { Education, and The Accounting Educators dergilerindeki } \\
\text { muhasebe eğitimi ile ilgili yayınların incelenmesi }\end{array}$ & $\begin{array}{l}\text { Hebele, Stephanie F. } \\
\text { Watson }\end{array}$ \\
\hline
\end{tabular}

Türkiye'de sosyal bilimler alanına yönelik birçok bibliyometrik araştırma yapılmıştır. Muhasebe -finansman alanında yapılan çalışmalar ise kısıtlıdır. Tablo 3'de Türkiye'de Muhasebe -Finansman alanında yapılan çalışmalar özetlenmiştir.

Tablo 3. Muhasebe-Finansman Alanında Türkiye'de Yapılan Araştırmalar

\begin{tabular}{|l|l|l|}
\hline Yll & Konu & Yazar \\
\hline 2007 & Denetim alanındaki çalışmaların analizi, & Selimoğlu ve Uzay \\
\hline 2007 & $\begin{array}{l}\text { 12. Dünya Muhasebe Tarihi Kongresi’nde Sunulan Türk } \\
\text { Akademisyenler ve Uygulamacıların Bildirileri’nin konu, yöntem } \\
\text { ve dönem açısından incelenmesi. }\end{array}$ & $\begin{array}{l}\text { Selimoğlu, } \\
\text { Güvemli }\end{array}$ \\
\hline 2008 & $\begin{array}{l}\text { İsletme Fakültesi Dergisi’nde 1972- 2007 yılları arasında } \\
\text { yayınlanan muhasebe finansman makalelerinin incelenmesi, }\end{array}$ & Sakin \\
\hline 2008 & $\begin{array}{l}\text { Muhasebe ve Bilim Dünyası Dergisi’nde 2004-2006 yılları } \\
\text { arasında çıkan muhasebe araştırmalarına yönelik atıf analizi, }\end{array}$ & Uysal \\
\hline 2009 & $\begin{array}{l}\text { Türkiye’de Muhasebe Eğitimi Literatürü (1998-2008) } \\
\text { Türkiye'deki akademik araştırma dergilerinde 2000-2008 yılları } \\
\text { arasında muhasebe alanında yayınlanan makalelerin analizi, }\end{array}$ & Önce ve Başar \\
\hline 2010 & $\begin{array}{l}\text { Türkiye ‘de Muhasebe alanında hazırlanan YÖK veri tabanında } \\
\text { kayıtlı lisansüstü tezlerin incelenmesi }\end{array}$ & Alkan \\
\hline 2014 & $\begin{array}{l}\text { Muhasebe ve Finansman Dergisi’nde Yayınlanan Makalelerin } \\
\text { Bibliyometrik Analizi }\end{array}$ & Hotamışlı ve Erem \\
\hline
\end{tabular}




\section{ARAŞTIRMANIN YÖNTEMI}

$\mathrm{Bu}$ araştırmanın amacı; Social Science Citation Index tarafından taranan bir dergide yayınlanan Türkiye adresli muhasebe-finansman yayınlarının incelenmesidir. Araştırma sonucunda yayın yapılan yıllar, yayın yapılan dergilerin dağılımı, çalışmaların yazar sayıları ve yayın yapan yazarların üniversiteleri hakkında bulgular elde edilmiş ve yorumlanmıştır.

$\mathrm{Bu}$ çalışma yapılırken öncelikle, WOS kapsamında yer alan ve SSCI veri tabanında bulunan 1 Ocak 1980-7 Aralık Aralık 2014 tarihleri arasında yayınlanmış Türkiye adresli "Yönetim veya İşletme veya İşletme Finansı" kategorisindeki tüm akademik çalışmalar sorgulanmıştır. Elde edilen 2.390 çalışma; Muhasebe, Finans, İnsan Kaynakları, Yönetim, Pazarlama, Üretim ve İşlemler Yönetimi, Uluslararası İşletme ve Ticaret, Turizm olarak alanlarına göre sınıflandırılmıştır. Sınıflandırma yapılırken anahtar sözcük, çalışmanın başlığı, yayınlandığı dergi ve yazarın çalışma alanına göre değerlendirme yapılmıştır.Web of Science ara yüzünde önce Türkiye adresli tüm akademik çalışmalar sorgulanarak bu sonuçlar "Yönetim veya İşletme veya İşletme Finansı" adlı Web of Science Kategorisi kullanılarak daraltılmıştır.

\section{ARAŞTIRMANIN BULGULARI}

Türkiye adresli Muhasebe ve Finans yazınının SSCI kapsamındaki durumunu incelemek amacıyla gerçekleştirilen bibliyometrik analizler, yıllara göre yayın sayısı, yayınların yazar sayıları, yazarların çalıştığı kurumlar ve üniversiteler, yayınların yer aldığı dergiler, en fazla atıf alan yayınlar ve bu yayınlara yönelik özelliklerin incelenmesi ekseninde gerçekleştirilmiştir

Yukarıda anlatıldığı gibi arama kriterlerinde zaman aralığı 1980'den günümüze olarak seçilmişti. Fakat 1980'den 1994'e kadar farklı disiplinlerde çalışmalar bulunurken bu yıllarda, 1980 yılındaki 2 adet kitap değerlendirmesi çalışması dışında SSCI tarafından taranan dergilerde yayınlanan bir muhasebe-finans çalışmasına rastlanamamıştır. $\mathrm{Bu}$ çalışma tasarlanırken, çalışmanın başlığı "Türk Muhasebe ve Finans Yazınının SSCI'da 35 Yılı" olarak planlanmış fakat bu bulgudan sonra "Türk Muhasebe ve Finans Yazınının SSCI'da 20 Y1lı" olarak güncellenmiştir.

\subsection{Yıllara Göre Yayın Sayıları}

1994-2008 y1lları arasında herhangi bir SSCI dergide yayınlanan makale sayısının oldukça durağan olduğunu görmekteyiz. İlk 15 yıl için yıllık ortalama yayın sayısı 5,47 ve standart sapması 3,59'dur. Hatta 1994 ile 1999 yılları arasındaki ilk 6 yılı dikkate aldığımızda yayın sayısı çok daha durağan bir seyir izlemiştir. 1994-2008 yıllardaki toplam yayın sayısı ise 82'dir. 15 yıllık zaman aralığ çalışmanın inceleyebildiği 21 yıllık zaman aralığı içindeki payı yaklaşık \%71 iken bu dönemde yayınlanan makalelerin toplam zaman aralığındaki yayınlar içindeki payı sadece yaklaşık \%21'dir. 
Y1llara göre yayın sayıları değerlendirildiğinde, 1994-2014 yılları arasında akademik yayın sayısında önemli bir artış gözlenmektedir. 2013 yılı 83 yayınla en fazla yayın yapılan yıldır. SSCI'da taranan dergilerde yayınlanan akademik çalışma sayısındaki en büyük sıçramanın 2009 yılında olduğunu görmekteyiz.

2008 yılında 11 olan yayın sayısı 2009'da 39'a çıkmış ve 2009 yılından itibaren artış devam etmiştir. Bu artışın temelinde yatan en önemli neden, 2009 yılında muhasebe ve finans makalelerinin de yayınlanmasına olanak sağlayan bir yerli derginin SSCI kapsamına alınmasıdır. İktisat İşletme Finans Dergisi bu yıldan itibaren SSCI kapsamına alınmış ve 2009'dan itibaren her yıl yayınlanan akademik çalışmaların önemli bir miktarı (6 yılda toplam 88 yayın) bu dergide yayınlanmıştır.

2009 yılındaki sıçramanın bir diğer nedeni de . İktisat İşletme Finans Dergisi’ bu yıl taranmaya başlanmasıdır. African Journal of Business Management dergisi de 2009 yılı ile SSCI kapsamından çıkarıldığı 2011 yılı arasında toplamda 34 akademik çalışmanın yayınlanması ile toplam yayın sayısına olumlu bir katkısı olmuştur.

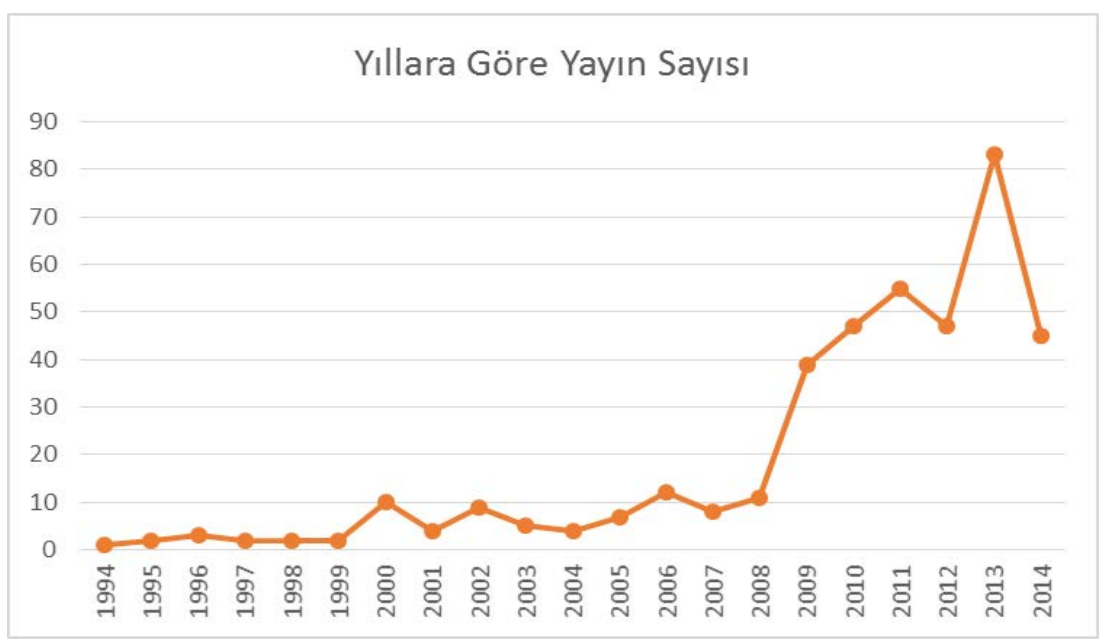

Şekil 1. Y1llara Göre Yayın Sayıları

2009 yılındaki yayın sayısındaki kayda değer sıçramanın yanında bir diğer önemli sıçrama da 2013 yılında yaşanmış ve 2013 yılında toplamda 83 adet muhasebe-finans çalışması SSCI tarafından taranan dergilerde yayınlanmıştır.

\subsection{Dergilere Göre Yayınların Dağılımı}

1994-2014 yılları arasında Türkiye adresli akademik çalışmalar toplamda 75 farklı dergide yayınlanmıştır. Yayınların yapıldığı dergileri incelediğimizde her ne kadar dergi sayısı yüksek görünse de dergilerde yüksek bir konsantrasyon görmekteyiz. En çok yayının yapıldığı 3 dergi olan "İktisat İşletme ve Finans", "Emerging Markets Finance and Trade" ve "African Journal of Business Management" adlı dergilerde toplam yayın sayısının \%50'sinin 
yayınlandığını görmekteyiz. 75 derginin 34'ünde sadece bir adet çalışma yayınlanırken, 13 adetinde sadece 2 makale yayınlanmıştır.

Tablo 4. Dergiler ve Yayın Sayıları

\begin{tabular}{|c|c|}
\hline DERGİ ADI & YAYIN SAYISI \\
\hline IKTISAT ISLETME VE FINANS & 88 \\
\hline EMERGING MARKETS FINANCE AND TRADE & 76 \\
\hline AFRICAN JOURNAL OF BUSINESS MANAGEMENT & 34 \\
\hline JOURNAL OF BANKING \& FINANCE & 17 \\
\hline JOURNAL OF BUSINESS ECONOMICS AND MANAGEMENT & 9 \\
\hline $\begin{array}{l}\text { EMERGING MARKETS REVIEW, JOURNAL OF REAL ESTATE FINANCE } \\
\text { AND ECONOMICS, RUSSIAN AND EAST EUROPEAN FINANCE AND } \\
\text { TRADE }\end{array}$ & 8 \\
\hline $\begin{array}{l}\text { CORPORATE GOVERNANCE-AN INTERNATIONAL REVIEW, } \\
\text { INTERNATIONAL JOURNAL OF FORECASTING, INTERNATIONAL } \\
\text { REVIEW OF ECONOMICS \& FINANCE, JOURNAL OF FORECASTING, } \\
\text { QUANTITATIVE FINANCE }\end{array}$ & 6 \\
\hline $\begin{array}{l}\text { JOURNAL OF FINANCIAL AND QUANTITATIVE ANALYSIS, JOURNAL OF } \\
\text { FINANCIAL ECONOMICS, JOURNAL OF FINANCIAL SERVICES } \\
\text { RESEARCH, JOURNAL OF INTERNATIONAL FINANCIAL MARKETS } \\
\text { INSTITUTIONS \& MONEY, NORTH AMERICAN JOURNAL OF } \\
\text { ECONOMICS AND FINANCE, REVIEW OF FINANCIAL STUDIES }\end{array}$ & 5 \\
\hline $\begin{array}{l}\text { FINANCE A UVER-CZECH JOURNAL OF ECONOMICS AND FINANCE, } \\
\text { JOURNAL OF EMPIRICAL FINANCE, JOURNAL OF FUTURES MARKETS }\end{array}$ & 4 \\
\hline $\begin{array}{l}\text { FINANCIAL MANAGEMENT, JOURNAL OF FINANCIAL STABILITY, } \\
\text { JOURNAL OF INTERNATIONAL MONEY AND FINANCE, MANAGEMENT } \\
\text { SCIENCE, MATHEMATICAL FINANCE, SERVICE INDUSTRIES JOURNAL }\end{array}$ & 3 \\
\hline $\begin{array}{l}\text { INTERNATIONAL JOURNAL OF CONSUMER STUDIES, INTERNATIONAL } \\
\text { JOURNAL OF CONTEMPORARY HOSPITALITY MANAGEMENT, } \\
\text { INTERNATIONAL JOURNAL OF STRATEGIC PROPERTY MANAGEMENT, } \\
\text { INTERNATIONAL REVIEW OF FINANCIAL ANALYSIS, JASSA-THE } \\
\text { FINSIA JOURNAL OF APPLIED FINANCE, JOURNAL OF BUSINESS } \\
\text { ETHICS, JOURNAL OF CORPORATE FINANCE, JOURNAL OF ECONOMICS } \\
\& \text { MANAGEMENT STRATEGY, JOURNAL OF PORTFOLIO } \\
\text { MANAGEMENT, MANAGEMENT ACCOUNTING RESEARCH, REAL } \\
\text { ESTATE ECONOMICS, TOTAL QUALITY MANAGEMENT \& BUSINESS } \\
\text { EXCELLENCE, WORLD ECONOMY }\end{array}$ & 2 \\
\hline
\end{tabular}




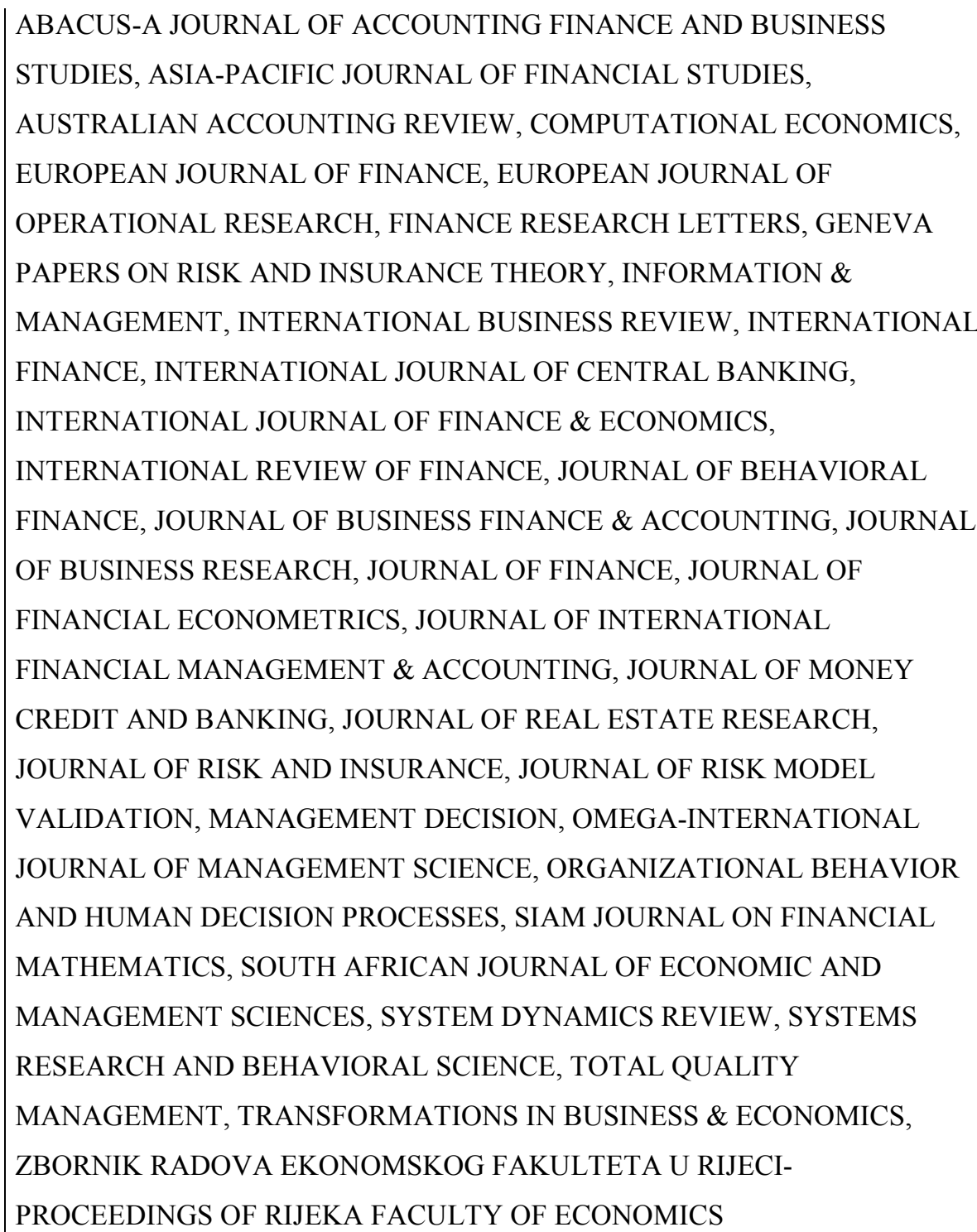


Tablo 5. En Fazla Yayının Yapıldığı Dört Dergi

\begin{tabular}{|c|c|c|c|c|c|}
\hline YIllar & IIF & EMFT & AJBM & JBF & Toplam \\
\hline $\mathbf{1 9 9 4}$ & & & & & $\mathbf{1}$ \\
\hline $\mathbf{1 9 9 5}$ & & & & & $\mathbf{2}$ \\
\hline $\mathbf{1 9 9 6}$ & & & & 1 & $\mathbf{3}$ \\
\hline $\mathbf{1 9 9 7}$ & & & & & $\mathbf{2}$ \\
\hline $\mathbf{1 9 9 8}$ & & & & & $\mathbf{2}$ \\
\hline $\mathbf{1 9 9 9}$ & & & & 1 & $\mathbf{2}$ \\
\hline $\mathbf{2 0 0 0}$ & & & & & $\mathbf{1 0}$ \\
\hline $\mathbf{2 0 0 1}$ & & & & & $\mathbf{4}$ \\
\hline $\mathbf{2 0 0 2}$ & & 6 & & 1 & $\mathbf{9}$ \\
\hline $\mathbf{2 0 0 3}$ & & 2 & & & $\mathbf{5}$ \\
\hline $\mathbf{2 0 0 4}$ & & 1 & & & $\mathbf{4}$ \\
\hline $\mathbf{2 0 0 5}$ & & 2 & & & $\mathbf{7}$ \\
\hline $\mathbf{2 0 0 6}$ & & 3 & & 1 & $\mathbf{1 2}$ \\
\hline $\mathbf{2 0 0 7}$ & & 2 & & 1 & $\mathbf{8}$ \\
\hline $\mathbf{2 0 0 8}$ & & 1 & & 2 & $\mathbf{1 1}$ \\
\hline $\mathbf{2 0 0 9}$ & 15 & 3 & 5 & & $\mathbf{3 9}$ \\
\hline $\mathbf{2 0 1 0}$ & 11 & 5 & 11 & 2 & $\mathbf{4 7}$ \\
\hline $\mathbf{2 0 1 1}$ & 13 & 8 & 18 & 1 & $\mathbf{5 5}$ \\
\hline $\mathbf{2 0 1 2}$ & 10 & 13 & & 3 & $\mathbf{4 7}$ \\
\hline $\mathbf{2 0 1 3}$ & 23 & 29 & & 2 & $\mathbf{8 3}$ \\
\hline $\mathbf{2 0 1 4}$ & 16 & 4 & & 2 & $\mathbf{4 5}$ \\
\hline TOPLAM & $\mathbf{8 8}$ & $\mathbf{7 6}$ & $\mathbf{3 4}$ & $\mathbf{1 7}$ & $\mathbf{3 9 8}$ \\
\hline
\end{tabular}

Tablodan görüldüğü gibi Journal of Banking and Finance (JBF) en az 1996 y1lından beri ve Emerging Markets Finance and Trade (EMFT) en az 2002'den beri SSCI tarafindan taranmaktadır. Daha önemlisi 2013 y1lı istisna olmak üzere bu iki dergide de istikrarlı ve durağan sayıda makale yayınlanmıştır.

Daha önce belirtildiği gibi 2009 ve 2012 yıllarındaki keskin düşüş ve çıkış African Journal of Business Management (AJBM) ve İktisat İşletme ve Finans (IIF) dergilerinden kaynaklanmaktadır. Bu iki dergideki yayınların sayısının hariç tutulması ile SSCI tarafından taranan bir dergide yayınlanan akademik çalışma sayısının trendi hakkında daha sağlıklı bir görünüm elde edilecektir. Bu iki derginin çıkarılmasının yanında Emerging Markets Finance and Trade (EMFT) dergisinin önceki yıllar ile kıyaslanamayacak ölçüde artış gösterdiği 2013 yılının etkisinin sıfırlanması ile ortaya çıkan trend grafiği Şekil 2'de gösterilmiştir. 


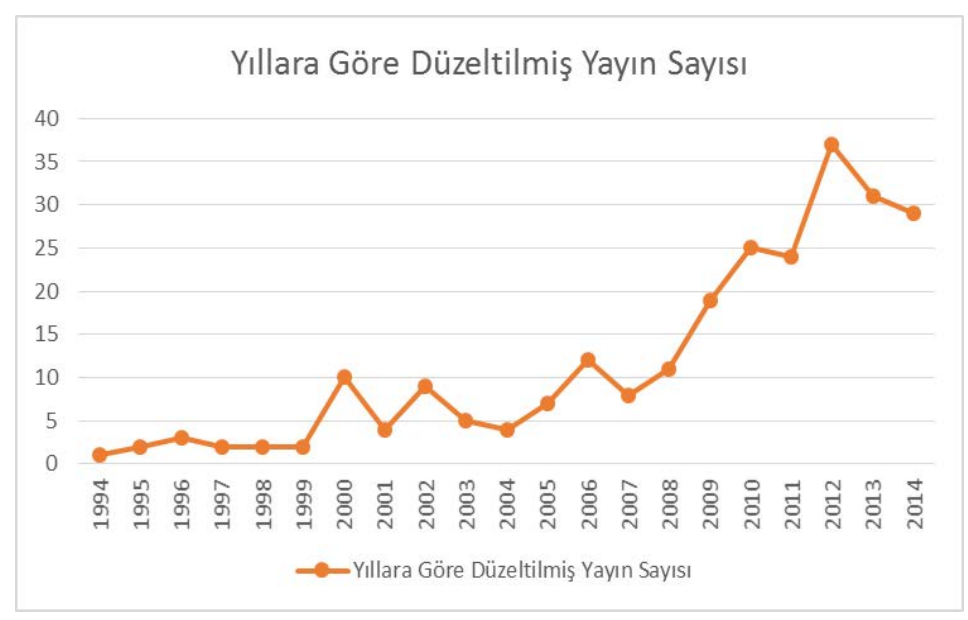

Şekil 2. Yı1lara Göre Düzeltilmiş Yayın Sayıları

Görüldüğü gibi yayın sayısında anormal yükselişe sebep olan faktörlerin etkileri elendiğinde bile, bazı yıllar hariç, Türk muhasebe ve finans yazınının son 20 yıl içinde yükselen bir trende sahip olduğunu söyleyebiliriz.

\subsection{Yayınların Yazar Sayılarına Göre Dağılımı}

Çalışmalar yazar sayılarına göre incelendiğinde iki yazarlı çalışmaların yoğunluğu görülmektedir. Muhasebe Finans alanındaki yayınların \%16'sı tek yazarlıdır. Çalışmaların $\% 51$ 'i iki yazarlı \%28'i ise üç yazarlıdır. Çalışmaların sadece \%5'i dört veya daha fazla yazar tarafindan hazırlanmıştır.

Tablo 6. Makalelerin Yazar Sayıları

\begin{tabular}{|c|c|c|}
\hline YAZAR SAYISI & $\mathbf{N}$ & YÜZDE \\
\hline $\mathbf{1}$ & 65 & $\% 16$ \\
\hline $\mathbf{2}$ & 203 & $\% 51$ \\
\hline $\mathbf{3}$ & 110 & $\% 28$ \\
\hline 4 ve daha fazla & 20 & $\% 5$ \\
\hline TOPLAM & 398 & $100 \%$ \\
\hline
\end{tabular}

\subsection{Yayınların Yazarların Bağlı Oldukları Üniversitelere Göre Dağılımı}

Web of Science'de yayınlanan Türkiye adresli Muhasebe Finans konusundaki yayınları yapan araştırmacıların bağlı oldukları üniversitelere göre dağılımı Tablo 7'de verilmiştir. 
Tablo 7. Yazarların Bağlı Oldukları Üniversiteler

\begin{tabular}{|c|c|}
\hline Bilkent Üniversitesi & 69 \\
\hline Boğaziçi Üniversitesi & 51 \\
\hline Koç Üniversitesi & 50 \\
\hline İzmir Ekonomi Üniversitesi & 38 \\
\hline Hacettepe Üniversitesi & 29 \\
\hline Dokuz Eylül Üniversitesi, Orta Doğu Teknik Üniversitesi & 27 \\
\hline Sabanc1 Üniversitesi & 22 \\
\hline Gebze Yüksek Teknoloji Üniversitesi & 16 \\
\hline Bülent Ecevit Üniversitesi, İstanbul Üniversitesi & 15 \\
\hline Marmara Üniversitesi, Doğu Akdeniz Üniversitesi, Fatih Üniversitesi & 13 \\
\hline Yıldız Teknik Üniversitesi & 12 \\
\hline İstanbul Bilgi Üniversitesi & 11 \\
\hline Özyeğin Üniversitesi & 10 \\
\hline Çukurova Üniversitesi, Gazi Üniversitesi, TOBB Üniversitesi, Yaşar Üniversitesi & 9 \\
\hline Çankaya Üniversitesi & 8 \\
\hline Anadolu Üniversitesi, Selçuk Üniversitesi, Süleyman Şah Üniversitesi & 7 \\
\hline Pamukkale Üniversitesi, Beykent Üniversitesi, Kadir Has Üniversitesi & 6 \\
\hline Akdeniz Üniversitesi, Osmangazi Üniversitesi & 5 \\
\hline $\begin{array}{l}\text { Abant İzzet Baysal Üniversitesi, Erciyes Üniversitesi, Nevşehir Üniversitesi, Sakarya } \\
\text { Üniversitesi, Uludağ Üniversitesi, Medeniyet Üniversitesi }\end{array}$ & 4 \\
\hline $\begin{array}{l}\text { Afyon Kocatepe Üniversitesi, Atılım Üniversitesi, Bahçeşehir Üniversitesi, TED Üniversitesi, } \\
\text { Yeditepe Üniversitesi }\end{array}$ & 3 \\
\hline $\begin{array}{l}\text { Balıkesir Üniversitesi, Galatasaray Üniversitesi, İstanbul Teknik Üniversitesi, Karadeniz Teknik } \\
\text { Üniversitesi, Mustafa Kemal Üniversitesi, Yıldırım Beyazıt Üniversitesi, Başkent Üniversitesi, } \\
\text { Doğuş Üniversitesi, Işık Üniversitesi, İpek Üniversitesi, İstanbul Aydın Üniversitesi }\end{array}$ & 2 \\
\hline $\begin{array}{l}\text { Adnan Menderes Üniversitesi, Bartın Üniversitesi, Bilecik Üniversitesi, Çanakkale On Sekiz } \\
\text { Mart Üniversitesi, Dumlupınar Üniversitesi, Mersin Üniversitesi, Muğla Sıtkı Koçman } \\
\text { Üniversitesi, Necmettin Erbakan Üniversitesi, Ondokuz Mayıs Üniversitesi, Orhangazi } \\
\text { Üniversitesi, Trakya Üniversitesi, Uşak Üniversitesi, Çağ Üniversitesi, İstanbul Ticaret } \\
\text { Üniversitesi, Kültür Üniversitesi, Maltepe Üniversitesi, Şehir Üniversitesi, Yüzüncü Yıl } \\
\text { Üniversitesi }\end{array}$ & 1 \\
\hline
\end{tabular}

SSCI tarafından taranan bir dergide yayınlanan Türkiye adresli Muhasebe Finans konusundaki yayınları yapan araştırmacıların bağlı oldukları üniversitelere göre dağılımı incelenirken toplam yazar sayısı da dikkate alınmıştır. Toplam 884 yazardan 844'ünün yayının yapıldığı tarihte çalıştıkları üniversiteler belirlenmiş ve sıralama yapılmıştır. 
Yayın yapan yazarlar toplamda 41'i devlet üniversitesi, 29'u vakıf üniversitesi olmak üzere 70 farklı üniversitede çalışmaktadır. Yazarların yaklaşık \%35'i (296) yazar Türkiye'deki bir devlet üniversitesinde çalışmakta iken, yazarların yaklaşık \%36'sı (307 yazar) bir vakıf üniversitesinde çalışmaktadır.

Ayrıca toplamda 71 yazar da başta Türkiye Cumhuriyet Merkez Bankası (32 yazar) ve Borsa İstanbul (21 yazar) olmak üzere çeşitli üniversite dışı yerli kurumlarda çalışmaktadır. Toplam yazar sayısının yaklaşık \%20'si (170 yazar) ise yurtdışındaki çeşitli üniversite ve kurumlarda çalışmaktadırlar.

Devlet üniversiteleri sıralamasında ise Hacettepe Üniversitesi, Dokuz Eylül Üniversitesi ve Boğaziçi Üniversitesi ile Orta Doğu Teknik Üniversitesi ilk üç sırada yer almaktadır.

Yazarların yaklaşık \%8'inin (69 yazar) Bilkent Üniversitesi'nde, \%6'sının (51 yazar) Boğaziçi Üniversitesi'nde, \%6'sının Koç Üniversitesi'nde ve \%4,5'unun (38 yazar) İzmir Ekonomi Üniversitesi'nde çalıştığı görülmektedir. İlk dört sırada yer alan üniversitelerde çalışan yazar sayısı toplam yayın yapan yazar sayısının yaklaşık \%25'ini oluşturmaktadır ve ilk dört üniversite içinde bir devlet üniversitesi ve üç vakıf üniversitesi bulunmaktadır.

\subsection{Yayınların Konularına Göre Dağılımı}

SSCI kapsamında yayınlanan Türkiye adresli muhasebe alanındaki makalelerin ağırlıklı olarak yoğunlaştıkları temel alanlar denetim, maliyet muhasebesi, muhasebe meslek etiğidir.

Tablo 8. Muhasebe Alanındaki Yayınların Konularına Göre Dağılımı

\begin{tabular}{|l|c|}
\hline \multicolumn{1}{|c|}{ KONU } & YAYIN SAYISI \\
\hline DENETIM & 5 \\
\hline MALIYYT MUHASEBESİ & 6 \\
\hline MUHASEBE BİLGİ TEKNOLOJILERİ & 3 \\
\hline MUHASEBE MESLEK ETIĞİ & 4 \\
\hline DEVLET MUHASEBESİ & 1 \\
\hline DİĞER & 5 \\
\hline
\end{tabular}

Konuları açısından değerlendirildiğinde maliyet muhasebesi konusundaki yayınların ağırlıklı olarak faaliyet tabanlı maliyetleme ve toplam kalite maliyetleri ile ilgili olduğu görülmüştür. Meslek etiği ile ilgili yayınlar meslek mensuplarına yönelik araştırmalardan oluşmaktadır. Meslek mensuplarının iş doyumu ve tükenmişlik sendromu iki çalışmada incelenmiştir. Muhasebe alanındaki çalışmalardan birinde etik konusu Türkiye ve Pakistan karşılaştırmalı olarak verilmiştir. Muhasebe bilgi teknolojileri konusundaki üç çalışmanın ikisi 2011 biri 2012 üçü 2014 yılında yapılmıştır. Bu çalışmaların ikisinde UFRS öncesi 
UFRS sonrası karşılaştırma yapılmış, diğer çalışmada ise işletme birleşmeleri incelenmiştir. 2014 yılında yayınlanan çalışmalardan biri Türkiye'de KOBİ TFRS konusunun incelemiştir. Türkiye'deki ulusal yayınlar incelendiğinde de 2010 yılından sonra UFRS konusundaki çalışmaların sayısal olarak arttığ

Tablo 9. Finans Alanındaki Yayınların Konularına Göre Dağılımı

\begin{tabular}{|c|c|}
\hline KONU & YAYIN SAYISI \\
\hline BANKACILIK & 52 \\
\hline FINANSAL RİSK YÖNETIMII & 37 \\
\hline HİSSE SENEDİ PİYASALARI & 49 \\
\hline $\begin{array}{l}\text { HISSSE SENETLERİNDE GETİṘ } \\
\text { HESAPLAMLARI }\end{array}$ & 30 \\
\hline KURUMSAL YÖNETIMM & 12 \\
\hline GAYRİMENKUL PİYASALARI & 14 \\
\hline VADELİ İŞLEM SÖZLEŞMELERİ & 9 \\
\hline $\begin{array}{l}\text { VALUE AT RİSK, İŞLETME } \\
\text { BİRLEŞMELERİ, PORTFÖY YÖNETIMİ }\end{array}$ & 8 \\
\hline FINANSAL KRİZ & 19 \\
\hline HEDGING, YATIRIM FONLARI & 17 \\
\hline FINANSAL GELIŞME & 6 \\
\hline $\begin{array}{l}\text { DÖVİZ PIYYASALRI, EKONOMİK } \\
\text { BELİRSİZLIK, FİNANSAL BİLGİ SİSTEMİ }\end{array}$ & 26 \\
\hline PETROL PIYYASASI & 5 \\
\hline $\begin{array}{l}\text { DAVRANIŞSAL FİNANS, FINANSAL } \\
\text { MODELLEME }\end{array}$ & 8 \\
\hline KREDİ DERECELENDİRME & 2 \\
\hline $\begin{array}{l}\text { FINANSAL HİZMETLER, FINANSAL } \\
\text { PERFORMANS }\end{array}$ & 2 \\
\hline BİREYSEL EMEKLİLİK SISTEMİ , BASEL II & 5 \\
\hline RİSK SERMAYESİ & 2 \\
\hline DİĞER & 83 \\
\hline TOPLAM & 386 \\
\hline
\end{tabular}

SSCI'da yer alan Türkiye adresli finans alanındaki çalışmaların \%14'ü bankacılık konusundadır. Bankacılık konusundaki 52 çalışmanın 20'si 2010-2012 yıllarında yayınlanmıştır. İlk çalışma 1997 yılında banka varlıkları ve borçları konusunda yayınlanmıştır. Finans konusunda en çok araştırılan konulardan biri de finansal risk 
yönetimidir. Konu ile ilgili 2002-2014 yılları arasında toplam çalışma yayınlanmıştır. Yayınların büyük çoğunluğunun uygulamaları BİST 100'deki şirketler üzerinde yapılmıştır. Hisse senedi piyasaları konusundaki çalışmalar gelişmekte olan piyasalara odaklanırken uygulamalar çoğunlukla Borsa İstanbul da yapılmıştır. Gayrimenkul piyasaları konunda SSCI'da yayınlanan 14 çalışmanın yarısı aynı araştırmacılar tarafından yapılmıştır.

\section{SONUÇ}

Araştırmanın bulgularından birisi vakıf üniversitelerinin sayılarının hem Türkiye genelinde hem de bu çalışma kapsamında devlet üniversitelerinden az olmasına rağmen daha fazla sayıda yazarın SSCI tarafından endekslenen bir dergide yayın yapmasıdır.

Vakıf üniversitelerinin kamudaki nitelikli araştırmacılara yönelik istihdam politikaları ve araştırmacılara yapılan yurt dişı yayın destekleri bu sonuca yansımaktadır. Vakıf üniversitelerinin öğrenci sayılarını arttırmaya yönelik çalışmalarında yayın sayısı bir veri olarak kullanılmakta ve bu bağlamda akademisyenlere yaptırımlar uygulanmaktadır. Vakıf üniversitelerinin ücret politikaları, akademisyenlerin daha az ders yükü ile çalışmalarını olanaklı hale getirmektedir. Akademik yükseltmelerde puan sisteminin değiştirilmesi son yıllarda, devlet üniversitelerinde SSCI yayınlarının sayısının artmasını etkileyen faktörlerden biridir.

Araştırmanın bir diğer bulgusu yayın sayısının 2009 yılında ve 2013 yılında bir önceki döneme göre kayda değer bir artış göstermesidir. Daha önce belirtildiği gibi yerli bir tane derginin bile SSCI kapsamına alınmasının Türkiye adresli ve çoğunlukla Türkiye finans ve muhasebe uygulamalarının çalışıldığı makalelerin tüm dünyada daha fazla bir kitleye ulaşabilmesindeki önemi bir kere daha gündeme getirmektedir. Çeşitli üniversitelerimizin, enstitülerimizin ya da özel kuruluşların çıkardıkları dergilerin saygın uluslararası endeksler tarafından taranabilir duruma gelmesi hem kurumlarımızın hem de diğer otoritelerin bilim politikasında öncelikleri arasında yer almalıdır.

Yıllar itibariyle yayın sayısında dikkat çeken bir diğer durum ise 2013 yılında yayın sayısındaki önemli orandaki artıştır. $\mathrm{Bu}$ artış 2009 yılındaki gibi yeni dergilerin SSCI kapsamına alınmasından kaynaklanmamaktadır. 2012 y1lı ve 2013 yılı arasındaki gözle görünür farkın altında önemli bir payı olan faktör kanımızca, 2012 Kasım ayında hazırlanan Yeni YÖK Yasa Tasarısında öngörülen doçentlik başvuru kriterlerindeki değişikliklerdir. Doçentlik sınavına başvuru için doktora belgesine sahip olduktan sonra beş yıl geçmiş olmasının öngörülen şartlardan birisinin olması bu yıldaki yayın sayısında bir artırıcı güç olması beklenebilir.

Yayın yapılan dergiler ile ilgili araştırmanın önemli bulgusu yayınların belli başlı dergilerde gruplanmış halde olduğudur. Dergiler anlamındaki yüksek konsantrasyon, yıllar itibariyle yayın sayısının istikrarı için önemli bir tehdittir. 2012 yılındaki yayın sayısındaki azalma aslinda sadece bir derginin (African Journal of Business Management) SSCI kapsamından çıkarılmasından kaynaklanmaktadır. Çeşitli sebeplerden dolayı en çok yayın 
yapılan diğer iki dergiden birinin veya her ikisinin birden SSCI kapsamından çıkarılması durumunda Türkiye adresli finans ve muhasebe yayınlarının uluslararasılaşması adına önemli bir tehdit olacağı açıktır.

\section{KAYNAKLAR}

AL, Pınar- Al, Umut - Bahşişoğlu, Hatice Kübra (2004), "Science Citation Index'de Hacettepe Üniversitesi: 1975-2003”, Hacettepe Üniversitesi Edebiyat Fakültesi Dergisi, 21(2), ss.229-244.

Al, Umut (2008), “Bilimsel Yayınların Değerlendirilmesi: h-Endeksi ve Türkiye'nin Performans1”, Bilgi Dünyas1, 9(2), ss.263-285.

Alkan, Gönül (2014),“Türkiye'de Muhasebe Alanında Yapılan Lisansüstü Tez Çalışmaları Üzerine Bir Araştırma (1984-2012)" Muhasebe ve Finansman Dergisi,Sayı:61, Ocak, ss. $41-52$

Arslantürk, Zeki (1995), Araştırma Metod ve Teknikleri, İstanbul: Marmara Üniversitesi Yayınları, No: 103, ss.14.

Apostolou, John M.-Hassell, James E.-Rebele, Stephanie -F. Watson,(2010), “Accounting education literature review (2006-2009), Journal of Accounting Education Volume 28, Issues 3-4, September, pp. 145-197.

Daniel C., Díaz- Hernández, E -Richard, Mattesich (2004), "Accounting Publications and Research in Spain: First Half of the 20th Century", Review of Accounting and Finance, Vol. 3 Iss: 3, pp.40 - 58.

Hotamışl1, Mustafa- Erem, Işıl (2014), "Muhasebe ve Finansman Dergisi'nde Yayınlanan Makalelerin Bibliyometrik Analizi”, Muhasebe ve Finansman Dergisi,Sayı:61, Temmuz, ss.1-20.

Catriona, Paisey - Nicholas, J. Paisey "An Analysis Of Accounting Education Research İn Accounting Education: An International Journal - 1992-2001” , Accounting Education: An International Journal, 13:1, pp.69-99.

Dinç, Engin-Çankaya, Fikret-Kaya,U., (2009), "Türkiye Muhasebe Eğitimi Literatürünün İncelenmesi( 1998-2008)", 28.Türkiye Muhasebe Eğitimi Sempozyumu'ndan aktaran Saime, Başar Banu, (2010), Türkiye'deki Akademik Araştırma Dergilerinde Muhasebe Alanında Yazılmış Makalelerin Analizi: 2000-2008” ,MUFAD Journal/Sayı 45 Ocak.

Mcmillan, J.- Guffy, D, (2006), “Twenty years of Advances in Accounting 19842003",aktaran Önce, S.,Başar, B., (2010),Türkiye'deki Akademik Araştırma Dergilerinde Muhasebe Alanında Yazılmış Makalelerin Analizi: 2000-2008, MUFAD Journal/Sayı 45 - Ocak 2010. 
Mc Burney, M. K. - Novak, P. L. (2002), "What is Bibliometrics and Why Should You Care?", Proceedings of the Professional Communication Conference, pp:108- 114.

Michael , Meyer - John, T. Rigsby (2001), "A Descriptive Analysis of the Content and Contributors of Behavioral Research In Accounting 1989-1998”. Behavioral Research in Accounting: February 2001, Vol. 13, No. 1, pp. 253-278.

Önce, Saime - Başar, Banu, (2010), “Türkiye'deki Akademik Araştırma Dergilerinde Muhasebe Alanında Yazılmış Makalelerin Analizi: 2000-2008”, MUFAD Journal/Sayı 45 - Ocak 2010,ss. 55-68

Paul, D. Hutchison, -Craig, G. White, (2003), "The Journal of the American Taxation Association 1979-2000: Content, Participation, and Citation Analyses”. The Journal of the American Taxation Association: Spring 2003, Vol. 25, No. 1, pp. 100-121.

Prather, Jenice J. -Rueschhoff, N., (1996), "An Analysis of International Accounting Research in U.S. Academic Accounting Journals, 1980 Through 1993”, Accounting Horizons, Vol 10, No 1, ss.1-17.

Richard, A. Bernardi (2005), “ Accountıng Scholars Publıshıng In Ethıcs Journals: A 30Year Longitudinal Study, in Cynthia Jeffrey (ed.) Research on Professional Responsibility and Ethics in Accounting (Research on Professional Responsibility and Ethics in Accounting, Volume 10", Emerald Group Publishing Limited, pp.63-93.

Selimoğlu, Seval Kardeş, Uzay, Şaban (2007),"10 Years of Research on Auditing in Turkey: A Literature Review", The Balkan Countries' 1st International Conference on Auditing and Accounting, 8-9 March, Edirne, Bildiri Kitab1, ss. 461-482.

Sakin, Turgay (2008), "A Content Analysis of Papers Published in the Journal of School of Business Administration: Accounting and Finance (1972 -2007)". İstanbul Üniversitesi İşletme Fakültesi Dergisi, Cilt/Vol:37, Sayı/No:1, ss.13-21.

Uysal, Ömür (2009). "Muhasebe Bilim Dünyası Dergisi Üzerinden (2004-2006)Muhasebe Araştırmalarının Bibliyometrik Analizi”, aktaran Önce Saime, Başar Banu, (2010),Türkiye'deki Akademik Araştırma Dergilerinde Muhasebe Alanında Yazılmış Makalelerin Analizi: 2000-2008 ,MUFAD Journal/Say1 45 - Ocak 2010.

Selimoğlu, Seval Kardeş-Aslan, Ü- Güvemli, Batuhan, (2007), “12. Dünya Muhasebe Tarihi Kongresinde Sunulan Türk Akademisyenler ve Uygulamacıların Bildirileri; Bir Literatür İncelemesi”, Muhasebe Finansman Dergisi, Ekim 2007,sayı:36,s.215 .

Uzay, Şaban - Seval K. Selimoğlu, (2007), Türkiye'de Muhasebe Denetimi Alanında Yapılan Araştırmalar (1995-2005) ve Seçme Yazılar, İstanbul Serbest Muhasebeci Mali Müşavirler Odası Yayını, Yayın No: 82, 432 sayfa, İstanbul.

Vigano, Enrico - Mattesich, R, (2007), Accounting Research in Italy; second half of twentieth century, Rewiev of Accounting and Finance (6),1,ss.24-41. 
Yavan, Nuri (2005), "SCI ve SSCI Bağlamında Türkiye'nin Coğrafya Biliminde Uluslararası Yayın Performansının Karşılaştırmalı Analizi: 1945-2005”, Coğrafi Bilimler Dergisi,2005,3 (1), 27-55.

Yılmaz, Bülent, (2002), "Konu, Ülke Orijini Ve Dil Dağılımı Açısından Atıf Dizinleri” (SCI ve SSCI). Bilim ve Ütopya, 94, 47-51.

Xu-Dong Ji (2000), "Evaluation Of Research On Chinese Accounting Issues", Managerial Finance, Vol. 26 Iss: 5, pp.41-62.

Zeff, Stephen, (1996), “A Study Of Academic Research Journals In Accountıng”,Accounting Horizons,Vol 10,No, 3,ss.158-177. 